American Journal of Applied Sciences 7 (11): 1439-1442, 2010

ISSN 1546-9239

(C) 2010 Science Publications

\title{
Prevalence of Obesity, Overweight and Underweight among Elementary School Children in Southern Iran, 2009
}

\author{
${ }^{1}$ Elham Ahmadi, ${ }^{1}$ Ali Rikhtegaran Tehrani and ${ }^{2}$ Akbar Ahmadi \\ ${ }^{1}$ Kerman Neuroscience Research Center, Kerman University of Medical Sciences, Iran \\ ${ }^{2}$ Department of Pediatrics, Kerman University of Medical Sciences, Iran
}

\begin{abstract}
Problem statement: In recent years obesity has become epidemic in children and adolescents and was one of the main problems in developed and developing countries. Considering the importance of obesity complications for the health state of society and its increasing rate, careful evaluation, monitoring and follow up of obesity in children and adolescents was of a great importance. The aim of the present study was to determine the prevalence of obesity, overweight and underweight in elementary schoolchildren in Kerman, Iran. Approach: This cross-sectional study was performed on 1566 elementary schoolchildren aged 7-11 years in Kerman/Iran in 2009. A questionnaire consisted of age, sex, type of school, parents' educational level, family size, weight and height was filled out for each student. Weight and height were measured by standard methods. Obesity, overweight and underweight based on Body Mass Index (BMI) were determined for age and sex and in comparison to standard percentiles of World Health Organization (WHO). Results: The prevalence of obesity, overweight and underweight was 9.7, 4.4 and $0.57 \%$ respectively. There was no significant relationship between BMI and gender. There was an increasing rate of obesity and overweight risk in children of parents with higher educational levels and the prevalence of underweight was higher in the students of public schools. No significant relationship was found between BMI and family size. Conclusion: Based on the results, although obesity was still relatively uncommon in 7-11 year old urban students, the more important problem was the increasing rate of obesity and overweight prevalence. Establishing interventional measures in order to prevent risky behaviors leading to obesity and overweight seems to be highly necessary.
\end{abstract}

Key words: Body Mass Index (BMI), nutritional status, prevalence of obesity, educational level, risky behaviors, protein-energy malnutrition

\section{INTRODUCTION}

In recent years obesity has become epidemic in children and adolescents and is one of the main health problems in developed and developing countries. According to the international definitions, at least $10 \%$ of children worldwide are suffering from obesity or overweight and the prevalence is increasing rapidly in a way that it has been estimated to be doubled by 2010 in elementary school children (Dorosti et al., 2009). From all obese schoolchildren, approximately $50 \%$ live in the United States, $40 \%$ in East Mediterranean (including Pakistan), $33 \%$ in west pacific islands and $20 \%$ in Southeast Asia (Dorosti et al., 2009). Considering the importance of obesity consequences on the health status of society and its rapidly increasing rate, careful evaluation, monitoring and follow up of obesity state in children and adolescents is essential. Since childhood obesity is highly probable to extend toward adulthood and this may be followed by psychological problems such as depression, it is much better to prevent obesity in overweight children rather than in adults (Kim et al., 2005).

There is little information about the prevalence rate of obesity and overweight in Iranian children. According to some studies, the prevalence has been increasing in the recent decade. In a study on elementary school girls in Tehran the prevalence rate of overweight and obesity have been 13.3 and $0.7 .7 \%$ respectively (Hajian et al., 2009).

On the other hand protein-energy malnutrition is one of the common nutritional problems in children less than 5 years of age in our country (Hajian et al., 2009). The most important complications of malnutrition are poor growth, risk of infections and ability decrease leading to fatigue, disability and psychological, social, economic, cultural, educational and health problems. In spite of significant measures in health system, Iranian

Corresponding Author: Akbar Ahmadi, Department of Pediatrics, Kerman University of Medical Sciences, Iran 
children are still involved with these problems (Karajibani et al., 2004). In a study on 7-10 years old female children in east of Tehran, the prevalence of underweight has been $28.9 \%$ and the prevalence of severe, moderate and mild wasting have been 0.7, 4.1 and $25.4 \%$ respectively (Karajibani et al., 2004).

In developing countries because of economic problems protein-energy malnutrition is still common in children aged 6-12 years (Hajian et al., 2009). Therefore, identifying the health state of children in relation to their anthropometric indices is very important. Increase of urbanization in the last two decades has lead to major changes of life style especially in children and created a good condition for the incidence of problems resulting from childhood obesity and overweight. Since there is no enough study about the prevalence of obesity in south Kerman, the present study aimed to find the prevalence of overweight, obesity and underweight in elementary school students of Kerman and comparing with the same study 10 years ago.

\section{MATERIALS AND METHODS}

This cross-sectional study was performed on 1566 elementary school children aged 7-11 years in Kerman the center of Kerman province located in Southern Iran. A total of 1566 children were enrolled into the study. After coordination with Kerman Education Office, subjects were selected by multi-stage clustering sampling method. That is, in the first step 12 girlschools and 13 boy-schools were selected and then by using proportion to size-based sampling and referring to the schools, each class was considered as a cluster. From each level one class was selected randomly and in each cluster (class) approximately 15 students (based on the total class population) were randomly selected for evaluation. A check- list including age, sex, type of school, parents' educational level, family size, weight and height was filled out for each student.

Weight was determined by standard method with the least clothing and using SECA scale with $\pm 500 \mathrm{~g}$ accuracy. Height was measured with SECA height measuring device $( \pm 0.1 \mathrm{~cm}$ accuracy). BMI [weight $(\mathrm{kg}) /$ height $\left.^{2}\left(\mathrm{~m}^{2}\right)\right]$ was calculated. WHO Standard percentiles of BMI (enclosed) were used for evaluation of overweight, obesity and underweight. That is, BMI of each subject was compared with the related standard index based on age and sex (De Onis et al., 2007).

Those with BMI of more than one SD were considered at risk of overweight (equal to BMI of 25 in 19 years of age) and those with BMI of more than 2 SD (equal to BMI of 30 in 19 years of age) were considered obese. Subjects with BMI of less than 2 SD were considered at risk of underweight and those with BMI of less than $3 \mathrm{SD}$ were considered as severe slim. Logistic regression was used for finding the relationship between underlying variables and the probability of over/underweight. Data analysis was done by SPSS17.

\section{RESULTS}

In whole, 1566 elementary school children in the age range of 7-11 years and mean age of $9 \pm 1.4$ years were studied. From whole, 1138 ones $(72.7 \%)$ were in public schools. Table 1 shows the frequency distribution of subjects based on their demographic features.

Mean $( \pm \mathrm{SD})$ of subjects' weight was $28.6 \pm 8.8 \mathrm{~kg}$, mean $( \pm \mathrm{SD})$ height was $132.2 \pm 10.9 \mathrm{~cm}$ and mean $( \pm \mathrm{SD})$ of their BMI was $16.0 \pm 3.0 \mathrm{~kg} \mathrm{~m}^{-2}$. BMI was compared based on demographic data (Table 2).

Table 1: Demographic features of studied students $(n=1566)$

\begin{tabular}{llcc}
\hline Variable & & Number & Percent \\
\hline Sex & Male & 770 & 49.2 \\
Type of school & Female & 796 & 50.8 \\
& Public & 1138 & 72.7 \\
& Private & 428 & 27.3 \\
Father's educational level & Illiterate & 99 & 6.3 \\
& Elementary & 183 & 11.7 \\
& Secondary & 256 & 16.9 \\
& High school & 561 & 35.8 \\
& University & 451 & 28.8 \\
Mother's educational level & Illiterate & 86 & 5.5 \\
& Elementary & 157 & 11.2 \\
& Secondary & 213 & 13.6 \\
& High school & 662 & 42.3 \\
Family size & University & 423 & 27.0 \\
& $\leq 5$ & 1297 & 82.8 \\
& $>5$ & 255 & 16.3 \\
\hline
\end{tabular}

Table 2: BMI based on demographic features

\begin{tabular}{llll}
\hline Variable & & Mean $( \pm$ SD $)$ & P \\
\hline Sex & Male & $16.0(2.9)$ & 0.638 \\
Type of school & Female & $16.1(3.1)$ & \\
& Public & $15.9(2.8)$ & 0.014 \\
& Private & $16.3(3.4)$ & \\
& Illiterate & $15.5(2.3)$ & \\
Father's educational level & Elementary & $15.5(2.1)$ & \\
& Secondary & $16.1(3.1)$ & 0.003 \\
& High school & $16.2(3.2)$ & \\
& University & $16.1(3.0)$ & \\
& Illiterate & $15.5(2.1)$ & \\
Mother's educational level & Elementary & $15.7(2.5)$ & \\
& Secondary & $16.0(3.0)$ & 0.029 \\
& High school & $16.1(3.2)$ & \\
Family size & University & $16.2(3.0)$ & \\
& $\leq 5$ & $16.1(3.0)$ & 0.392 \\
& $>5$ & $16.0(3.0)$ & \\
\hline
\end{tabular}


Am. J. Applied Sci., 7 (11): 1439-1442, 2010

Table 3: The frequency distribution of severe wasting, wasting, overweight and obesity based on age and sex

\begin{tabular}{lllllll}
\hline Age & Sex & Severe wasting & Wasting & Normal & Overweight & Obesity \\
\hline 7 & Male $(\mathrm{n}=154)$ & $5(3.2)$ & $17(11)$ & $128(83.1)$ & $3(1.9)$ & $1(0.6)$ \\
& Female $(\mathrm{n}=159)$ & $1(0.6)$ & $17(11)$ & $136(85.5)$ & $5(3.1)$ & 0 \\
8 & Male $(154)$ & $6(3.9)$ & $12(8)$ & $132(86)$ & $2(1.3)$ & $2(1.3)$ \\
& Female $(159)$ & $2(1.3)$ & $14(9)$ & $139(87.4)$ & $3(2)$ & $1(0.6)$ \\
9 & Male $(\mathrm{n}=155)$ & $4(2.6)$ & $13(8.4)$ & $125(80.6)$ & $10(6.5)$ & $3(2)$ \\
& Female (n=158) & $3(2)$ & $14(9)$ & $135(85.4)$ & $6(3.8)$ & 0 \\
10 & Male $(\mathrm{n}=153)$ & $7(4.6)$ & $17(11.1)$ & $123(80.4)$ & $5(3.3)$ & $1(0.7)$ \\
& Female $(\mathrm{n}=160)$ & $4(2.5)$ & $16(10)$ & $124(77.5)$ & $16(10)$ & 0 \\
11 & Male $(\mathrm{n}=154)$ & $4(2.6)$ & $17(11)$ & $119(77.3)$ & $13(8.4)$ & $1(0.6)$ \\
& Female (n=160) & $6(3.8)$ & $16(10)$ & $132(82.5)$ & $6(3.8)$ & 0 \\
\hline
\end{tabular}

Table 4: Comparison of obesity and wasting based on type of school

\begin{tabular}{lllllll}
\hline Type of school & Severe wasting & Wasting & Normal & Overweight & Obesity & P \\
\hline Public & $26(2.3 \%)$ & $107(9.4 \%)$ & $957(84 \%)$ & $46(4 \%)$ & $2(0.2 \%)$ & 0.002 \\
Private & $16(3.8 \%)$ & $46(10.8 \%)$ & $336(78.5 \%)$ & $23(5.4 \%)$ & $7(1.6 \%)$ & \\
\hline
\end{tabular}

The distribution of severe wasting, wasting, overweight and obesity based on age and sex and type of school are shown in Table 3 and 4, respectively.

\section{DISCUSSION}

The prevalence of overweight and obesity in the studied subjects were 4.4 and $0.5 \%$ respectively. The corresponding values in Hajian et al. (2009) study on 712 years elementary school students in Babol were 12.3 and $5.8 \%$ respectively. The prevalence of overweight and obesity have been 34.5 and $26.2 \%$ respectively in Nunez-Rivas et al. (2003) study on 7-12 years children and 25.3 and $5.6 \%$ in Krassas et al. (2001) study on 610 years children. According to Kim et al. (2005) study these values for South Korean 8-18 years girls have been 12.5 and $65.6 \%$ respectively.

Ahmadi and Janghorbani (1998) study on Kerman elementary school students, the prevalence of obesity was found to be $0.4 \%$. It should be mentioned that the difference between the results of the mentioned study and the present study is due to variations in definitions and criteria for classifications. The prevalence of overweight and obesity in the present study are significantly less than what have been reported for Greece and South Korea and this can be attributed to different geographical regions and studied age groups.

The prevalence of underweight and severe wasting in our subjects were $9.7 \%$ and $2.5 \%$ respectively while, underweight prevalence has been $13.5 \%$ in a study in Babol (Hajian et al., 2009) and $45.1 \%$ in Kapil and Sethi (2004) study in Delhi. In South Korea study, the prevalence of underweight in 8-18 years girls has been $12.1 \%$ (Kim et al., 2005) and it has been $52 \%$ in Shariff et al. (2001) study in Kualalampur.

A study conducted in Bengal have reported $27.9 \%$ and $23 \%$ prevalence for underweight and wasting respectively (Bose and Bisai, 2008). In a study in Kerman/ Iran in 1998, these rates were 56.3 and $41.2 \%$ (Ahmadi and Janghorbani, 1998). The great difference between the mentioned study and this study is attributable to the changes in classifications and also changes in life style. In whole, the prevalence of underweight in the present study differed with the results of performed studies in Delhi (Kapil and Sethi, 2004), South Korea (Kim et al., 2005) and Kualalampur (Shariff et al., 2001). The differences might be because of the effective factors on growth and difference in sampling methods, selected age groups and socioeconomic and nutritional status among studies.

In the present study, there was no significant difference between the two sexes in regard to the prevalence rate of obesity and underweight, while in South Korea and Kualalampur studies (Kim et al., 2005; Shariff et al., 2001) the prevalence of obesity and underweight were significantly higher in boys than in girls. In Bengal (Bose and Bisai, 2008) and Delhi (Kapil and Sethi, 2004) studies, the prevalence of underweight has been significantly higher in boys than in girls. This difference between the two sexes might be due to the differences of growth patterns in the two sexes and the differences in nutritional habits and other health behaviors among children.

In the present study, there was a significant relationship between BMI and the educational level of father and mother $(\mathrm{p}=0.029$ and $\mathrm{p}=0.003$ respectively). There was also a significant relationship between the type of school (public or private) and BMI $(\mathrm{p}=0.014)$. If attending private schools is considered as better social and economic state, overweight and obesity are more common in students with better economic status. In a study conducted in Northern Iran the prevalence of underweight in public schools has been significantly higher than that in private schools 
(Hajian et al., 2009) that is in line with the results of the present study. The main cause of these findings is the effect of socio-economic factors on the growth status of children.

\section{CONCLUSION}

In this study, no significant relationship was found between family size and BMI in comparison to standard percentiles of Kerman elementary school students that are similar to the results of relevant studies (Hajian et al., 2009).

The results of the present study in comparison to similar studies in 1998 show that although underweight is still present in 7-10 years urban students, the more important issues are increasing rates of overweight and obesity which shows a transition toward overweight and obesity in children. Therefore, interventional programs for preventing high risk behaviors leading to overweight and obesity is highly necessary.

\section{REFERENCES}

Ahmadi, A. and M. Janghorbani, 1998. A study on obesity and wasting among primary school students of Kerman. J. Hamadan University Med. Sci., 6: $15-24$. http://www.umsha.ac.ir/design/pdf/chekide/ch11-3.pdf

Bose, K. and S. Bisai, 2008. Prevalence of underweight and stunting among school children in west Bengal. Indian J. Pediatr., 75: 1272. PMID: 18810360

De Onis, M., A.W. Onyango and E. Borghi et al., 2007. Development of a WHO growth reference for school-aged children and adolescents. Bull. World Health Organ., 85: 660-667. PMCID: PMC2636412

Dorosti, A., A. Houshyarrad, B. Ahrabkhani and F. Siasi, 2009. Determination of the most relevant body mass index standard reference to define obese Iranian school age children. Iran. J. Nut. Food. Indus. $\quad$ Sci., $\quad 4$ : 71-80. http://www.nsft.ir/browse.php?a_code=A-10-1$112 \&$ sid=1\&slc_lang=fa
Hajian, K., P. Sajadi and A. Rezvani, 2009. Prevalence of overweight and underweight among primary school children aged 7-12 in Babol. J. Babol Univ. Med. Sci., 10: 83-91. www.jbums.com/download.asp?code=MJBU8710383

Kapil, U. and V. Sethi, 2004. Prevalence of undernutrition amongst children (6-9 years) in Delhi. Indian Pediatr., 41: 628-9. PMID: 15235177

Karajibani, M., F. Montazerifar, M. Mohammadi and A.R. Dashipour, 2004. Prevalence of obesity and wasting among primary school girls of Zahedan. Tab. Shargh J., 6: 289-296. www.sid.ir/Fa/VEWSSID/J_pdf/66513830407.pdf

Kim, E., J.Y. Hwang, E.K. Woo, S.S. Kim and S.A. Jo et al., 2005. Body mass index cutoffs for underweight, overweight and obesity in south Korean school girls. Obes. Res., 13: 1510-4. PMID: 16222050

Krassas, G.E., T. Tzotzas and C. Tsametis et al., 2001. Prevalence and trends in overweight and obesity among children and adolescents in Thessaloniki, Greece. J. Pediatr. Endocrinol. Metab., 14: 1319-1326. http://www.ncbi.nlm.nih.gov/pubmed/11964029

Nunez-Rivas, H.P., R. Monge-Rojas and H. Len et al., 2003. Prevalence of overweight and obesity among Costa Rican elementary school children. Rer Panam Salad Publica., 13: 24-32. DOI: 10.1590/S1020-49892003000100004

Shariff, Z.M., J.T. Bond and N.E. Johnson, 2001. Nutritional status of primary school children from low income Households in Kualalampur. Mal. J. Nutr., $\quad 6$ : 17-32. http://nutriweb.org.my/publications/mjn006_1/mjn 6n1_art2.pdf 